occasion, 20 or so ticks off my skin, not giving them time to dig in. They are easy to remove if it is done promptly after a walk through their habitat.

Ticks can transmit a variety of arbovirus and rickettsial infections to man, but probably rarely do so in Britain. Some 33 cases a year of $\mathrm{Q}$ fever are reported in Scotland. Possibly some of these may have been transmitted by tick bites but probably most infections are acquired through milk, meat, or the handling of infected animals or their afterbirths.

\section{David Stevenson}

Department of Tropical Community

Health,

Liverpool School of Tropical Medicine,

SIR,-With reference to the inquiry from Dr J A Slater (29 October, p 1158) I acquired a tick on my wrist in September while birdwatching in the Breckland region of Norfolk. I disposed of my tick by the method I learnt to use in Central Africa-by lighting a match, blowing it out, and applying the hot end immediately to the tick. It was then possible to pull the tick out, head and all. I suffered no discomfort or induration.

M E R GRAY

London SW 15

\section{Red faces in Tavistock Square}

SIR,-May I offer a postscript to "Anti-goats" (22 October, p 1079)?

The "herd instinct of trotters" was not the right phrase

Which your erudite readers will note with amaze.

In fact I intended a far different word,

Viz, the late Wilfred Trotter's "Instincts of the Herd."

W E SNELL

Hambleden,
Henley-on-Thames, Oxon

\section{Effect of calcium deposition on copper IUDs}

SIR,-We were interested in Mr J Guillebaud's letter (10 September, p 705) and wish to enter the debate. The recent work of Dr Christine Gosden and others (22 January, p 202) and of Dr E Chantler and others from this department ( 30 July, $p$ 288) indicates that there is a rapid fall in the rate of copper release after the intrauterine contraceptive device (IUD) has been in situ for a few months. Further studies from our group ${ }^{1}$ indicate that there is a biochemical change in the endometrium associated with the use of copper IUDs and that this persists when the level of copper release has dropped considerably.

However, prolonged contraceptive efficacy can be determined only by long-term clinical data. Furthermore, we are concerned that advice with direct reference to its medicolegal implications should be given without confirmatory scientific fact. While we would concur with $\mathrm{Mr}$ Guillebaud's reservations about the selection of the two groups in the study reported from King's College Hospital (Mr J R Newton and others, 22 January, $p$ 197), the performance of the copper IUD which has been in situ for two years does not appear to deteriorate after this time. In addition there are considerable and far-reaching implications if copper IUDs are shown to be effective for more than two years. Indeed, there are data which would suggest that this might well be the case.

The accompanying table shows the cumulative event rates in a small series of women with Copper 7 IUDs which have been in situ for up to three years in Southampton. The device was fitted to 1752 women. The incidence of all three major IUD complications Life table rates per 100 fittings ( $\pm S E$ )

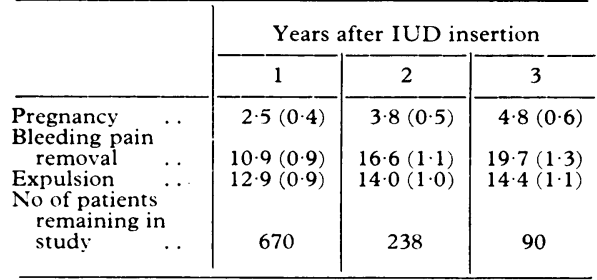

decreases with time and there is nothing to suggest that the fall in rate of copper release is associated with a rise in pregnancy rate. This is in keeping with the data presented by Edelman et al," who have presented figures for five years, and with those for the "continuation group" cited by Mr Newton and his colleagues.

On the basis of the evidence presented to date on the pregnancy rate of women wearing copper-carrying IUDs for longer than two years we would recommend that these IUDs can be safely left in situ for longer than two years. Indeed, a case could be made for them to be left in situ for up to five years if the lead of Zipper, who developed the concept of the copper IUD, is to be taken, since he is a coauthor of the report by Edelman et al.

\section{University Department of Human
Reproduction and Obstetrics, Southampton General Hospital,} Southampton

J F MILLER

Department of Obstetrics and

Max Elstein

Department of

University Hospital of South

Manchester

Manchester

Edelmann, D A, et al, IPPF Medical Bulletin, 1977, 11, No 4 .

${ }^{*}{ }^{*}$ This correspondence is now closed.-ED,

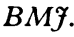

\section{Demand for patient care}

SIR,-Dr H G Pledger's letter (22 October, p 1084) raises a number of important points which are covered in the official reports. ${ }^{1}$ The number of beds available at the time of our survey in the Northern Area of Northern Ireland (24 September, p 799) was such that waiting for admission was the exception rather than the rule, so that it was reasonable to assume that there was virtually no unmet need for hospital admission in the community. As the population is geographically scattered, hospitals tend to be small and subsequently provide only mainstream specialties. Orthopaedics, ophthalmology, and paediatrics (which includes only medical paediatrics and not child patients of all specialties) are much more economically and effectively managed in the teaching hospitals in the capital city of Belfast, which has a population of half a million (a third of the Province) and is not more than 70 miles from the most extreme point of the
Northern Area. While the principle that a district should be self-contained for hospital services is administratively tidy, it seems more often than not to be unrealistic and impractical.

Our survey included patients living in social services residential accommodation. Unlike Great Britain, the health and social services have been integrated in Northern Ireland under one administrative structure so that regular contact with residential homes by district nurses is ensured. There are no private nursing homes in the area.

The catchment population of "about 300000 " was derived from analysis of admissions to hospitals in the Northern and adjacent Areas. As such it is open to the vagaries of the estimating procedure. The total is the sum of the effective catchment populations of all the hospitals, and local opinion supports the estimates for individual hospitals. Obviously 4 beds per 1000 is subject to greater variation. Not only does it incorporate any errors in the population estimate but it also mirrors the inherent weaknesses in the estimate of the beds required. Hence we felt it was, at best, only reasonable to suggest the magnitude of the demand in round figures: adjusting for occupancy creates a false sense of accuracy.

In writing the paper our main aim was to stimulate debate on the important issue of the provision of expensive acute beds and to suggest a simple method for a critical review of the use of present resources. Despite the limitations of the estimates we are convinced, and Professor C S B Galasko agrees (22 October, p 1083), that many inpatients in acute hospitals today could be equally well cared for in less highly staffed and equipped accommodation. If true, this has clear implications for the planning and financing of health services.

S Donaldson

\section{Department of Health and Belfast}

A BARR

Oxford Regional Health Authority, ' Northern. Health and Social Services Board, Develop-
ment of Hospital Services (2 volumes). Ballymena, NHSSB, 1976.

\section{The drug bill}

SIR,-Dr J F Lowe's suggestion that an "E" box be added to the EC 10 to enable dispensers to substitute a cheaper brand or $B P$ equivalent seems to commend itself (15 October, p 1024). But the implications need to be fully assessed.

The dispensing pharmacists are already aware of the difficulties in helping patients to take their drugs according to the instructions on the prescription. To add to their difficulties may bè unwise. There are many occasions when the instructions involve a modification of the previous dosage. The alert patient will generally reconsult the general practitioner to check that the change is in order. Others might not do so. But if the appearance of the tablets - their colour, size, or shape-is different considerable problems arise. Not least of these is the danger that the patient will take excessive dosage. The ready identification of branded drugs plays as important a role in their use as the memory-baffling "official" nomenclature, if not greater. It is perhaps unfair to the chemist to force him to become an arbitrator for the NHS in regard to the cost of individual 
items. To know that if they fail to keep up to date with the extensive list of drugs and their respective prices they will suffer financial penalties will indeed further demoralise our pharmacist colleagues. Moreover, it will not avail the druggist to try stocking only the cheaper versions. Not infrequently wholesalers will issue "competitive" lines, a well-known ploy to capture a market. Moreover, let us remember the disturbing example in the past of "cheap" ampicillin and also of penicillamine.

From the patients' point of view ready identification, especially for elderly people, is very important. They are often on long-term medication and frequently on two or more drugs. If the repeat prescriptions are liable to change their appearance the wastage in discarding the previously used (left-over) drugs will outweigh any saving in item costs. The dangers of duplication of dosage and of unused drugs lying around present serious problems. Family practitioners will have to familiarise themselves with a much larger range of products. Not least, they will have to be able to be quite sure that the tablets in the container are consistent with the name on the label. In my experience a surprising number of patients really do change their containers around.

Before this " $E$ " box is adopted the disadvantages must be considered. The "NP" box seemed a good idea, but in practice has increased the numbers of patients who are more or less self-medicating. It has also increased the number of patients who make statements that they are "allergic" to this or that or are suffering from side effects. Any family practitioner who cares to check will soon verify that patients now "look up" their drugs, not infrequently in $M I M S$, a great number of copies of which are circulating in the community. The "child-proof" container has been a mixed blessing; far too high a percentage of drugs are now left around exposed to moist air because of difficulties in opening these containers. On balance, the benefits to the economy of the national drug bill are doubtful. The extra problems resulting are many.

Turvey, Beds

S W V Davies

\section{Modified jejunoileal bypass for obesity}

SIR,-I was interested to read Professor A Cuschieri's speculative letter (15 October, p 1028) in which he defined a critical length of residual ileum based upon small-bowe measurements in his own patients.

Backman and Hallberg ${ }^{1}$ showed the length of the small intestine in 88 subjects to range from 4.0 to $10.2 \mathrm{~m}$, being longer in obese patients than in their controls. My own measurements in obese patients have been in agreement with their observations and we thus differ considerably from the measurements of Professor Cuschieri. Possibly this is due to different methods of measurement: most surgeons who perform the small-bowel bypass measure the stretched antimesenteric border, as this clearly would be longer than the unstretched mesenteric border. If the latter technique is used it is likely that excessive small bowel would be left "in circuit" and the patient would not lose weight.

When the end-to-side jejunoileostomy technique is used there is often considerable retrograde reflux into the excluded ileum.
Barium meal follow-through examinations carried out one year after the procedure have shown that as much as $60-90 \mathrm{~cm}$ may be filled, thereby making a considerably greater ileal absorptive surface available. I doubt therefore whether Professor Cuschieri's measurements are reliable and I do not think they are appropriate in the context of end-toside jejunoileostomy.

In ileal bypass procedures for hyperlipidaemia $200 \mathrm{~cm}$ of ileum is excluded with no problem of liver failure. In small-bowel bypass for massive obesity most surgeons have retained lengths of ileum less than the critical figure which Professor Cuschieri quotes, but the incidence of severe liver problems is low. I feel, therefore, that there is much more to the cause of liver failure after small-bowel bypass than the concept of critical lengths of residual ileum. I am worried that by excluding more jejunum the risk of protein malabsorption and consequent protein-carbohydrate malnutrition is likely to be more hazardous to the liver.

\section{R M BADDELEY}

General Hospital, Birmingham

'Backman, L, and Hallberg, D, Acta Chirurgica
Scandinavica, 1974, 140,57.

\section{Analgesia for fractured limbs}

SIR,-Having recently sustained a displaced fracture of the neck of the humerus I would heartily endorse Dr K B Queen's experience (Personal View, 15 October, p 1020) of the inadequate pain relief of $100 \mathrm{mg}$ of pethidine (one-third intravenously in my case) for a severe limb fracture. The subsequent lift on and off the stretcher and removal of jacket etc, in casualty were excruciatingly painful, but oh, the bliss and relief of pain after $15 \mathrm{mg}$ of morphine an hour later, despite its causing vomiting in the evening. The next painful four nights at home were relieved considerably with $15 \mathrm{mg}$ of Cyclimorph subcutaneously without causing vomiting, and I would urge general practitioners first on the scene of a severe limb fracture to give injectable morphine, preferably mixed with an antiemetic instead of pethidine.

I A Crowther

Dunblane, Perthshire

\section{Donor blood for neonatal exchange} transfusion

SIR,-Although the main indication for neonatal exchange transfusion, rhesus haemolytic disease, is now relatively rare, there still appears to be disagreement as to the optimum or indeed safe, age of the donor blood used.

A brief survey of nine departments of haematology in my own region reveals that, while all provide blood in acid-citratedextrose or citrate-phosphate-dextrose (CPD) and partially remove the plasma, there is considerable variation in the age of the blood provided. Two laboratories provide blood four days old or less, four provide blood three days old or less, two provide blood two days old or less, and one is usually asked for fresh donor blood but can often only provide blood up to two days old.

There are well-documented dangers in providing fresh blood straight from a donor before serological testing for hepatitis or syphilis, apart from the other communicable disease and immunological hazards. However, some paediatricians regard the dangers of fresh blood as less important than those associated with stored blood more than two days old. Standard testbooks quote 4- or even 5 -day-old blood as suitable in terms of citrate and potassium toxicity, and the use of CPD as an anticoagulant has improved the known falloff in 2,3-diphosphoglycerate and therefore oxygen release.

It would be valuable to know, therefore, whether any unpublished definitive information is now available which would indicate that the traditional practice of using serologically tested blood up to four days old is outmoded and that fresher blood should be used.

J P Lee-Potter

Department of Pathology,
Poole General Hospital,

Poole, Dorset

\section{Antibiotics for presumed viral} respiratory infections

SIR,-We wish to reply to Dr K R Woodcock's criticisms (17 September, p 772) of our paper on the effects of amoxycillin and co-trimoxazole on presumed viral respiratory infections in childhood (27 August, p 552).

(1) Dr Woodcock has misunderstood the conclusions from our study. In contradiction to most similar investigations ${ }^{1-3}$ our findings show small but statistically significant effects between the antimicrobial- and placebotreated groups. However, in our opinion the size of these differences does not justify the routine use of antimicrobials in presumed viral respiratory infections in childhood. As we said in our article, had the failure rate for the placebo-treated group prevailed for all subjects in the study this would have resulted in an extra three-tenths of one consultation per doctor per week. The point at issue is not whether antimicrobials have an effect but whether the size of this effect justifies routine prescription. In our opinion the cost of antimicrobials, the risk of sensitisation, the possibility of side effects, and the problems of the development of drug-resistant strains of bacteria in the community far outweigh threetenths of a consultation per doctor per week and the other marginal benefits shown in our analysis.

(2) Dr Woodcock appears to disavow any statistical expertise and from the table it is easy to see why. He presents a failure score which is the result of summing up the numbers who failed to complete the experiment and the numbers with purulent sputum, sore throat, wheezy chest, or fever on the eighth day of the trial. This summation is arithmetically incorrect, since these numbers do not represent mutually exclusive and exhaustive failure groups. A child could suffer fever, runny nose, and sore throat on day eight; by Dr Woodcock's arithmetic such a child would count as three failures. Leaving aside the basis of the statistic, such a score is misleading, since it combines several different criteria of failure into a global percentage. The purpose of our paper was to avoid this fallacy by analysing individual symptom patterns rather than presenting a single and dubious failure statistic. In reality all that Dr Woodcock has done is to combine some of the individual effects that we demonstrated throughout the paper into an inaccurate score which crudely represents exactly what we were saying. 